\title{
Conventional and advanced borehole investigation methods for inaccessible underground voids
}

\author{
M Pak Golder Associates Ltd., Canada \\ RP Preston Golder Associates Ltd., Canada \\ C Groccia Golder Associates Ltd., Canada \\ J Taylor Golder Associates Ltd., Canada
}

\begin{abstract}
Determining mitigation and remediation options for underground voids, such as those associated with active or abandoned underground mine development openings and mined out stopes, can be difficult due to limitations of safe access, flooding, and void geometry uncertainty. Recent advances and improved technology associated with borehole investigation methods are making the job easier and more cost-effective. Specialised cameras used to conduct investigative surveys through boreholes have been applied to solve such problems for many years. Recent advances in electronics, digital cameras, and low-cost production have allowed for a wider use of the technology. Other borehole-based tools such as cavity monitoring systems/LIDAR for dry voids, and borehole-based sonar for flooded voids can be used in conjunction with borehole camera surveying to maximise the data that can be collected through expensive boreholes. These methods greatly reduce uncertainty by providing high-resolution scaled models of the intersected void. The ability to collect an enhanced dataset for a small incremental cost, relative to the cost of drilling, improves the cost benefit by reducing uncertainty. The benefits and challenges associated with each borehole investigation method, as well as considerations for optimising the quality of data collected, are discussed using examples from Giant Mine in the Northwest Territories, Canada and the Kam Kotia Mine and the Mine N claim in Ontario, Canada.
\end{abstract}

Keywords: borehole investigation, cavity monitoring system, sonar scanner

\section{Introduction}

Inaccessible underground voids are common in the mining industry. Underground openings such as stopes, drifts, raises, and shafts often require a survey or inspection of their geometry and location when their stability is being assessed or they are being backfilled. Often during reclamation, because of the age of the workings and site history, access to the underground void is no longer safe or available, so the best option is to drill a hole that intersects the void and to perform the survey or inspection remotely.

Several borehole-specific investigation methods are currently available and widely used in the remediation process for underground voids. Borehole camera surveys, cavity monitoring system (CMS) surveys, and sonar surveys can all serve this purpose depending on the project requirements and site conditions.

The Giant Mine Remediation Project in the Northwest Territories, Canada and the Kam Kotia Mine and the Mine $\mathrm{N}$ claim in Ontario, Canada are examples of abandoned underground mines that pose a potential risk to the environment and the public. These are case studies of when the aforementioned remote borehole-deployed investigation methods were effectively utilised. 


\section{Case study site descriptions}

Background on the Giant Mine Remediation Project in the Northwest Territories, and the Kam Kotia Mine and the Mine $\mathrm{N}$ claim in Ontario are outlined in the following sections.

\subsection{Giant Mine background}

Giant Mine in Yellowknife, Northwest Territories, is a gold mine with open pit and underground aspects. The mine went into receivership in 1999 and is under remediation by the Indigenous and Northern Affairs Canada.

\subsection{Mine N claim background}

The stope is located on an abandoned mine claim, referred to as Mine $\mathrm{N}$ in this paper, which was operated in the early 1900s. The name of the mine has been changed to keep the identity of the client anonymous. The property is now held by a mining company that is in the process of assessing and reclaiming the hazards caused by the historical mining that occurred on the site.

\subsection{Kam Kotia Mine background}

The Kam Kotia Mine in Timmins, Ontario, was a copper mine that operated from 1943 to 1972 and is now a mine rehabilitation project owned by the Ontario Ministry of Northern Development and Mines (MNDM).

\section{Borehole deployment investigation methods}

\subsection{Borehole camera surveys}

The main objectives of a borehole camera survey are to inspect the general condition of the rock in the borehole and assess the position of the borehole breakthrough relative to the walls of the underground void to verify if other borehole investigative methods are possible. Borehole cameras are generally compact, and most units can fit in an NQ-size borehole $(75.7 \mathrm{~mm}$ diameter), providing real-time visual data at depths of $600 \mathrm{~m}$ in dry or flooded conditions.

The camera surveys are generally conducted before any other borehole investigation method as they are the quickest, easiest, and most inexpensive method. In addition, the camera includes a pan/tilt function that allows the user to rotate the camera $360^{\circ}$ on the horizontal axis and tilt the camera $180^{\circ}$ on the vertical axis (Allegheny Instruments, Inc. 2016).

The main challenges are that the borehole camera does not output enough light to inspect workings at longer distances greater than $1 \mathrm{~m}$, and the camera does not produce any scaled measurements of the underground void. The borehole camera head has eight built-in LED lights, and the working range of visibility is generally limited in voids greater than $1 \mathrm{~m}$ due to the limited illumination. To address this shortcoming, secondary custom LED light matrices outputting over 1,000 lumens are often lowered down the borehole ahead of the camera to provide additional illumination in the void and observe up to $35 \mathrm{~m}$ away in the void. Observations from a borehole camera survey with and without secondary lighting into an underground stope at Giant Mine are shown in Figure 1. 

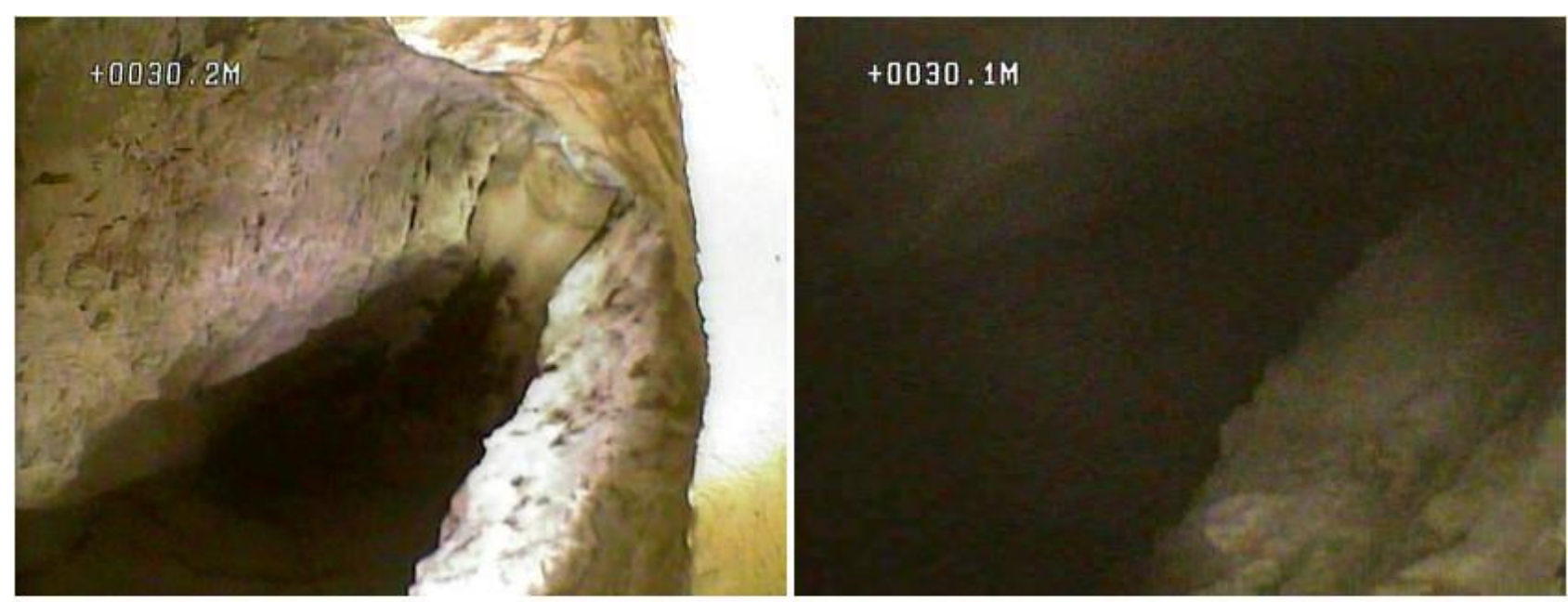

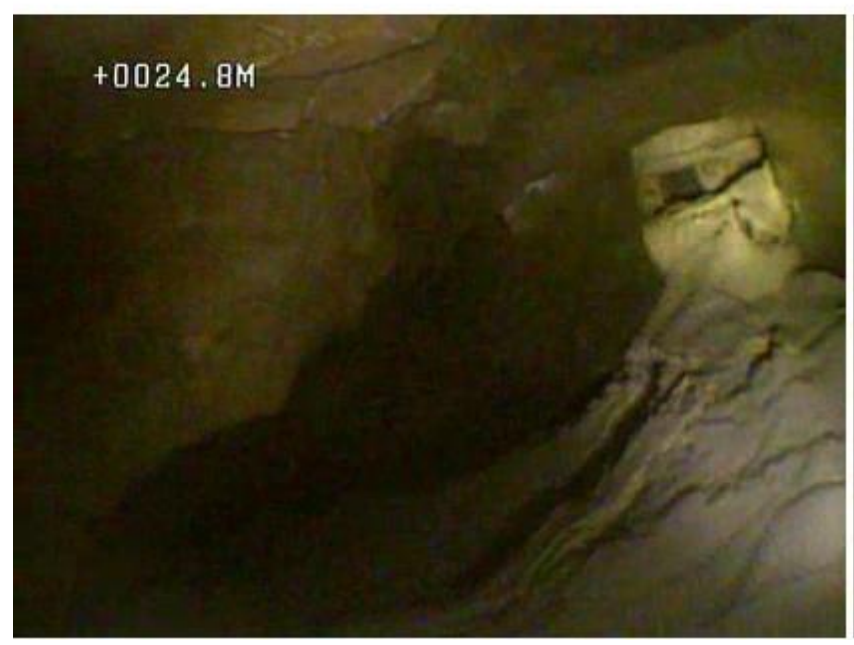

(a)

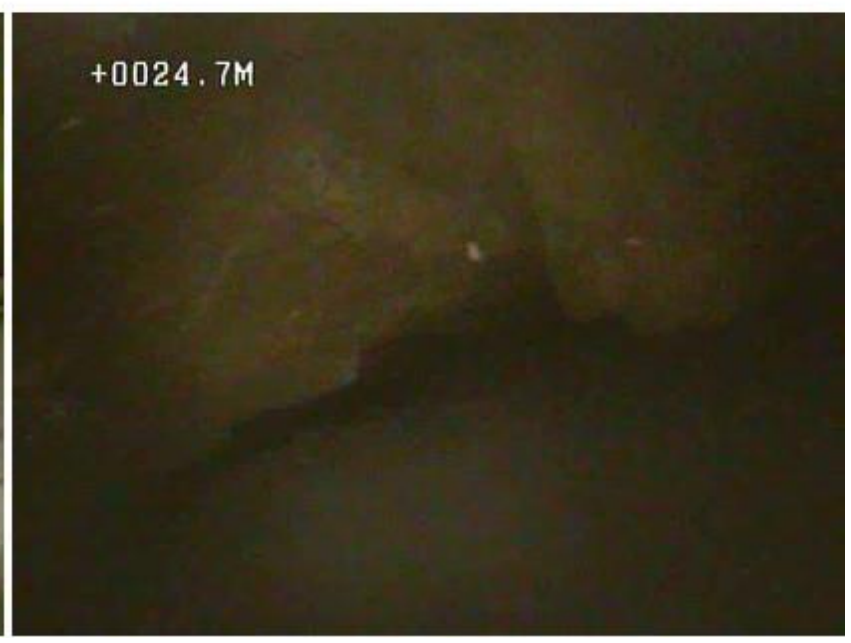

(b)

Figure 1 Borehole camera survey observations into underground stopes with (a) and without (b) secondary custom LED lights

Additionally, borehole camera surveys are more challenging in flooded conditions than in dry conditions. Suspended particulate in the water, and the difficulty in utilising additional external lighting increase the complexity of borehole surveys in flooded void space. As such, when flooded conditions are encountered, borehole surveys are often limited to an inspection of the breakthrough conditions or confirmation of the presence and depth of backfilling in the void space.

Despite advances in photogrammetry methods and software, generating representative 3D models from borehole camera surveys is often impossible due to the single viewpoint nature of the survey. In addition, without objects of known size within the field of view, scale can be difficult to interpret. As a result, borehole camera surveys are often used to confirm the presence, absence, or condition of underground workings and rock masses, but not for detailed surveying.

Borehole cameras, like all borehole investigation methods, are vulnerable to hang-ups if allowed to pass too far past the borehole breakthrough into the excavation. As a result, it is critical to plan borehole locations such that they intersect the void at an optimal location and angle to maximise view angles. However, irregularities in the void profile cannot be accounted for from surface, and can result in occlusion of the survey. 


\subsubsection{Borehole camera survey observation of rock walls and breakthrough conditions}

Underground stabilisation activities rely heavily on borehole camera surveys to mitigate the underground hazards present at Giant Mine. As part of the quality assurance work for drilling investigation programs at the Giant Mine Remediation Project, borehole camera surveys were completed to observe underground openings and assess the breakthrough condition to determine if a CMS could be safely conducted in the void. Borehole camera surveys were also used to observe the general condition of the rock in the borehole (e.g. check for presence of any open voids above the stopes or faults). Examples of breakthrough conditions are shown in Figure 2.
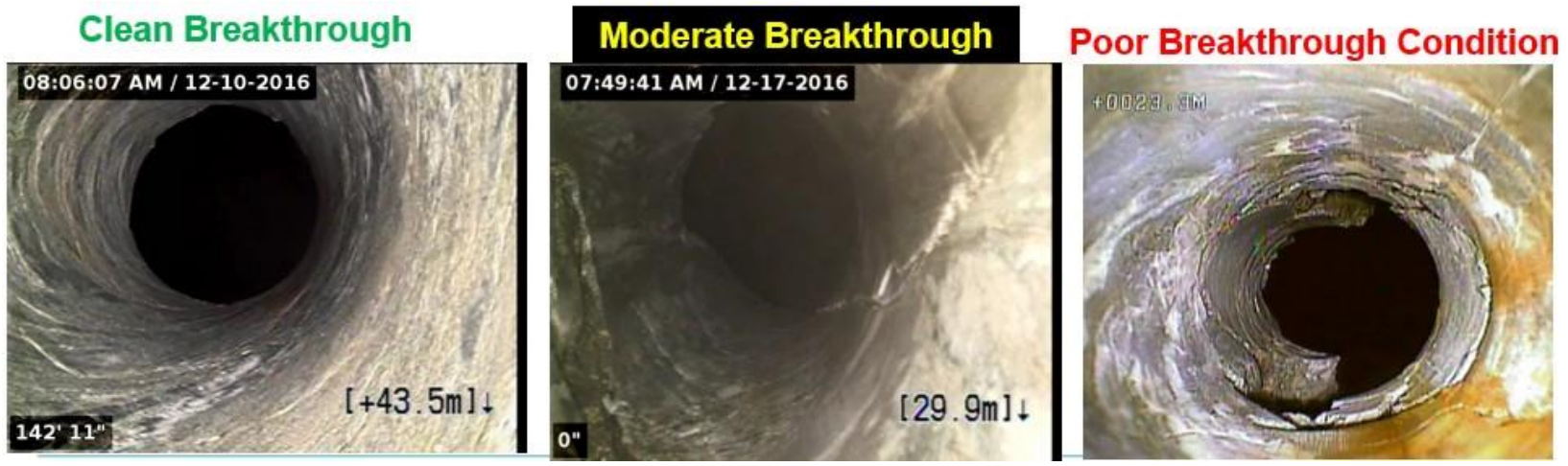

Figure 2 Borehole camera survey observations of breakthrough condition into underground voids

\subsection{Borehole cavity monitoring systems}

Borehole-deployed CMSs have proven to be useful tools for surveying inaccessible underground openings such as stopes, shafts, raises and drifts of abandoned mines. Golder Associates uses a Cavity Auto-scanning Laser System (C-ALS) that is $50 \mathrm{~mm}$ in diameter and provides complete $360^{\circ}$ coverage with a maximum azimuth resolution of $0.1^{\circ}$ and a range of $150 \mathrm{~m}$ under ideal conditions (Renishaw plc 2017). The C-ALS is equipped with a camera and two LEDs that face down the hole when the unit is being deployed. The camera is used to inspect the borehole during deployment, and to identify the exact depth at which the hole breaks into the underground void. It provides a view of parts of the void that are within a few metres but have insufficient light to see further.

The C-ALS is deployed with a load-bearing data transmission cable and a set of rigid hinged rods attached to the back end that prevent the C-ALS from rotating in the borehole. By surveying the collar of the borehole and rigid rods outside the borehole on surface, the location of the collar and the azimuth of the hole can be determined. As the C-ALS is deployed, the dip of the hole is measured at user-defined intervals so that the dip and deviation of the borehole can be determined and used with the collar location and borehole azimuth to calculate the location of points collected during the scan in whatever coordinate system is being used for the project.

For the C-ALS to capture a successful scan, the void must not be flooded, and the air must be free of excessive dust. When an underground void is backfilled through holes drilled from surface, the air in the void often becomes very dusty, and if sufficient time is not allowed for the dust to settle before performing a scan, the C-ALS unit's laser will not be able to penetrate through the dust, and the resulting scan will only show an erroneous spherical cloud of points around the head of the unit.

The final product of a successful survey is a 3D point cloud that is properly located and oriented in whatever coordinate system is being used. Depending on the needs of the project, this information can be used to calculate the volume of the void, monitor backfilling of the void and potential backfill leakage points, determine the thickness of the crown pillar and plan additional boreholes required to break into the void. 


\subsubsection{Cavity monitoring system survey of a stope}

To assist in the assessment of hazards at Mine N, Golder helped locate the stope and performed CMS surveys to determine the stope's orientation, dip and crown pillar thickness. This information was collected to assess the stability of the crown pillar. The stope has a raise that connects the top of the stope to surface. The first CMS survey, shown in Figure 3, was conducted by lowering the C-ALS into the raise and performing a quick low-resolution scan from the bottom of the raise. This was enough information to determine how far the C-ALS should be lowered for the second scan in order to optimise the data collected and avoid hitting the C-ALS on the footwall side of the stope.

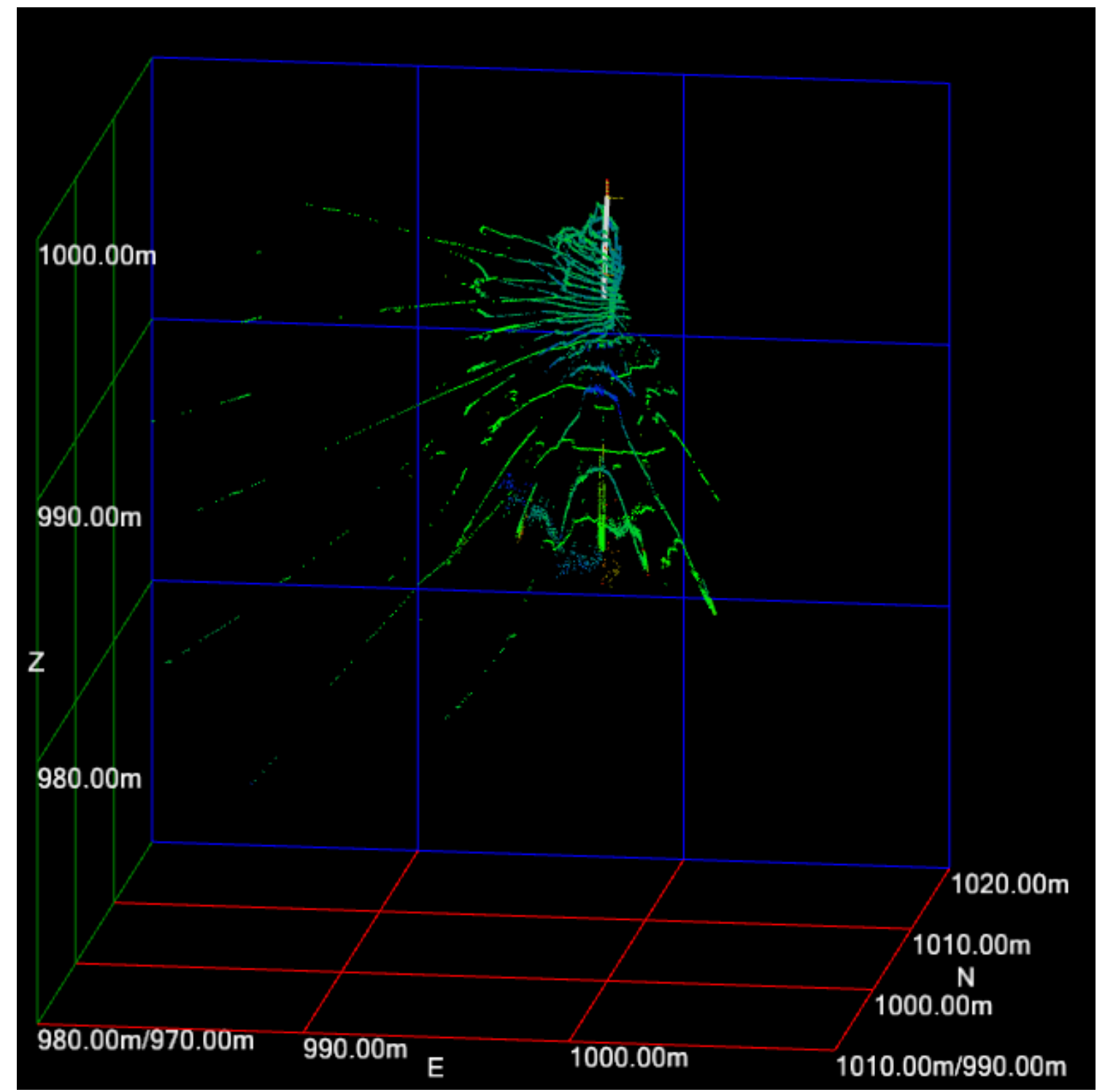

Figure 3 First C-ALS CMS survey of the Mine $\mathrm{N}$ stope from the bottom of a raise (raise that the C-ALS was deployed from is shown in white)

The shape of the stope prevented the entire stope from being captured in the second CMS survey, however, the information this survey provided was used to plan a borehole from which a third CMS survey was performed that did capture the remainder of the stope as shown in Figure 4. 


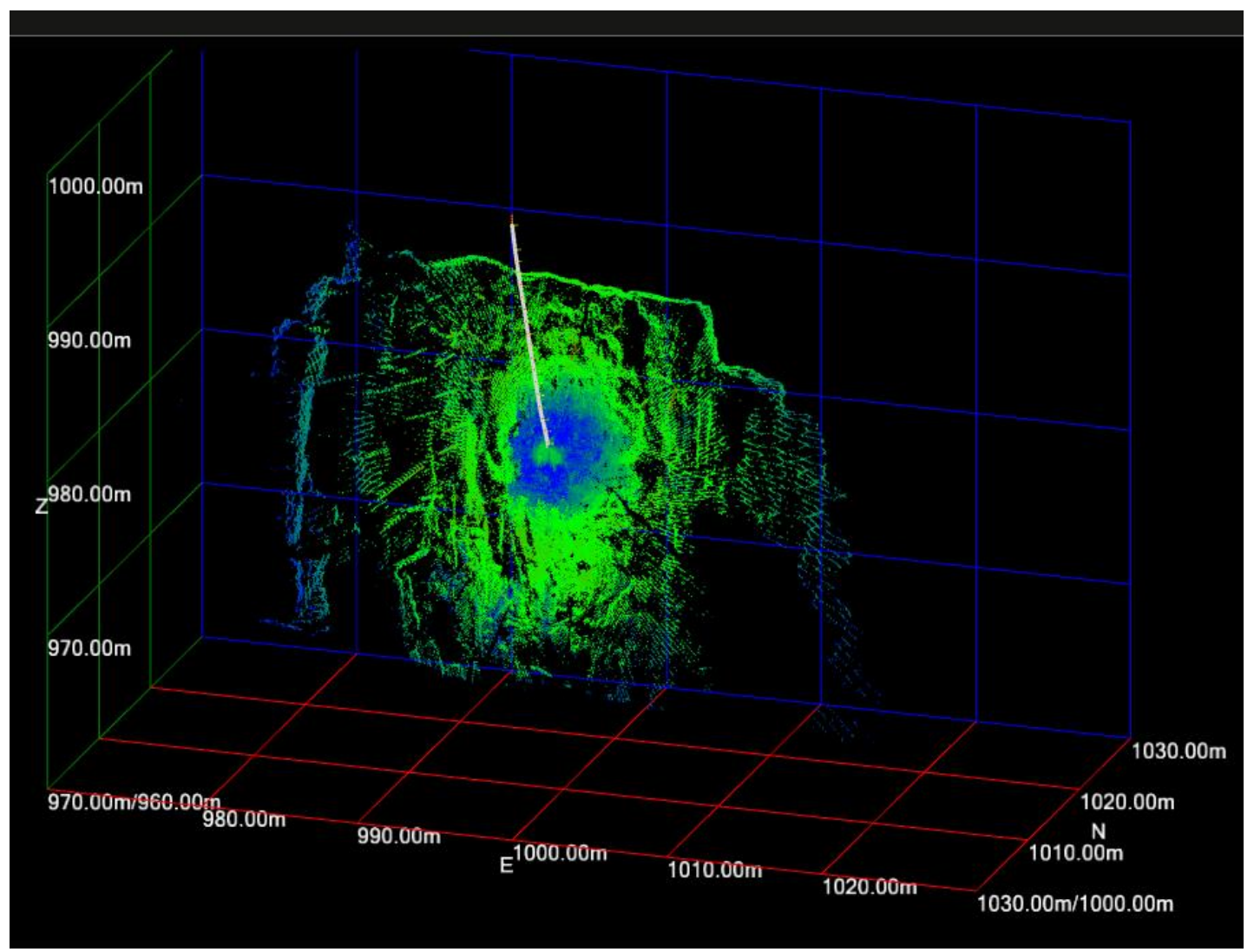

Figure 4 The third C-ALS CMS survey of the Mine $\mathrm{N}$ stope from the bottom of a borehole (borehole that the C-ALS was deployed from is shown in white)

A longitudinal projection of the third CMS survey of the stope was superimposed on a scaled copy of the only known historical drawing of the stope, and the two were found to be very similar, as shown in Figure 5 . The historical drawing indicates that the stope continues deeper than what is shown by the CMS survey. Based on the flat bottom of the CMS survey, observations made in the field with a borehole camera, and the historical drawing, it can be confidently concluded that the stope does continue deeper, but is flooded up to the bottom of the CMS survey. This information collected by the CMS surveys was used for a crown pillar stability assessment of the stope.

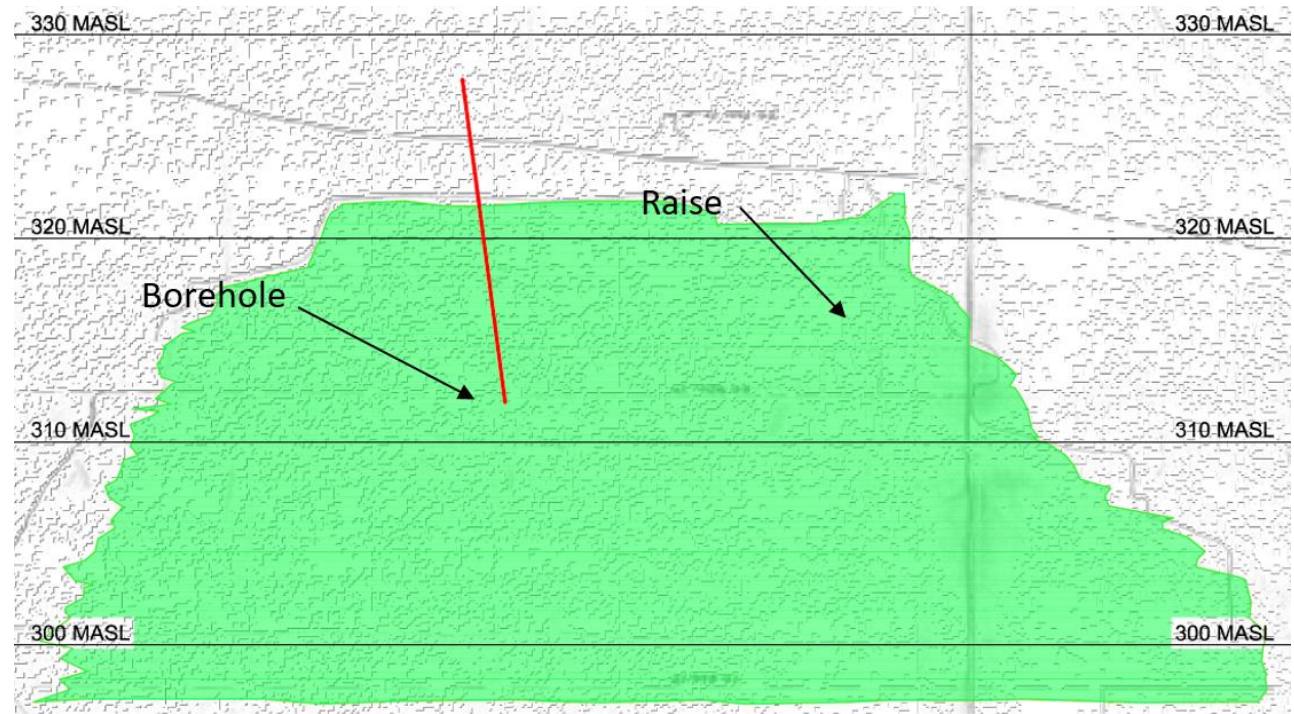

Figure 5 Longitudinal projection of the third CMS survey of the Mine N stope superimposed on a scaled historical drawing of the stope (the borehole that the C-ALS was deployed from shown in red) 


\subsection{Borehole sonar scanner}

During investigation stages of abandoned mines, flooded stopes or underground voids are often encountered. Flooded excavations present an additional challenge because water and sediment can significantly reduce sight distance for borehole cameras and prevent the use of borehole CMS surveys. However, by using a compact sonar sensor such as the Imagenex 881A (Imagenex Technology Corp. 2016), initially designed for bathymetric work from boats, the geometry of a flooded underground void can still be surveyed through $\mathrm{HQ}$-sized boreholes. The instrument has a range of $150 \mathrm{~mm}$ (minimum) to $100 \mathrm{~m}$ (maximum) and scans in a single, horizontal, beam pattern (Imagenex Technology Corp. 2016). To survey an entire stope, consecutive rings of point data are collected at regular elevation intervals, and the combined ring scans output point cloud data which can then be used to create a wireframe model of the scanned area. The resolution of the point cloud is dependent on the interval frequency of ring scans and the user-selected scanning speed of the sonar probe. A plan view example of a sonar ring scan of the $9900 \mathrm{~B} 1$ Stope from the Kam Kotia Mine is shown in Figure 6.

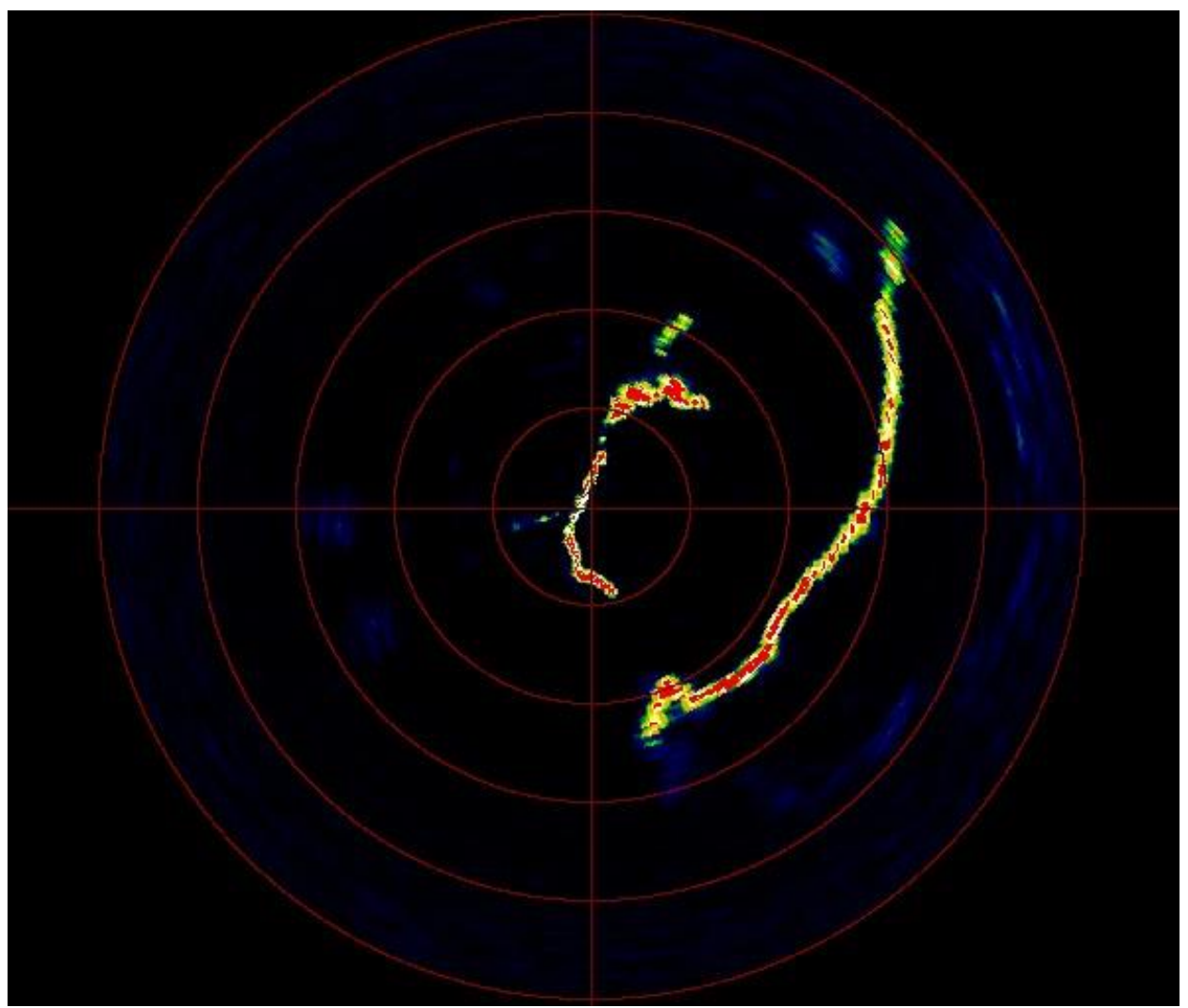

Figure 6 Plan view of a borehole sonar ring scan of the 9900B1 Stope

Similar to borehole camera surveys, borehole sonar is limited by the characteristics of the intersection between the borehole and the void. Often, the full height of an underground stope or void cannot be captured if the location of the borehole(s) misses the crown or if objects within the stope occlude the scanner's view, such as rubble or undulations in the stope wall. As the borehole sonar scanner generates ring scans perpendicular to the sonar head, it is not possible to capture objects directly above or below the scanner. As a result, it is best practice to locate the insertion borehole as close to the absolute crown of the void as possible. Placing the scanner insertion hole as close to the crown as possible can also be advantageous to avoid hang-ups during tool retrieval. As the sonar scanner is the only borehole instrument which is fully inserted into the void, it is particularly vulnerable to being caught on angularities or protrusions around the borehole breakthrough. As a control measure, the borehole camera survey is conducted to assess the breakthrough condition and determine if a borehole sonar is possible. Vertical boreholes are generally preferred as there is little to no risk getting the probe stuck at the breakthrough point. 
The scanner is currently lowered on a flexible communications cable, which makes surveying the scan using the same methods as the CMS impossible. However, it is equipped with a magnetic compass to correct for minor rotations which may occur as the tool is lowered during a scan. The compass, like all magnetic devices, is vulnerable to interference from nearby ferrous materials, which should be identified from the preliminary borehole camera survey. Although the raw scans are not georeferenced, they can be located by identifying previously surveyed points within the scan or by fitting to other surveys using surface fitting algorithms.

\subsubsection{Underwater sonar survey}

Sonar surveys were completed through six large-diameter boreholes using the newly acquired sonar profiler. The instrument was lowered to the breakthrough of each borehole, then lowered into the stope at $1 \mathrm{~m}$ increments, and ring scan sections were captured perpendicular to the instrument head until the sonar was obstructed (e.g. on footwall). The combined ring scans created a point cloud. Cross-sections traced vertically through the point cloud and a wireframe of the void shape were constructed. The wireframe models of the scanned volume, along with the MNDM boreholes, are shown in Figure 7.
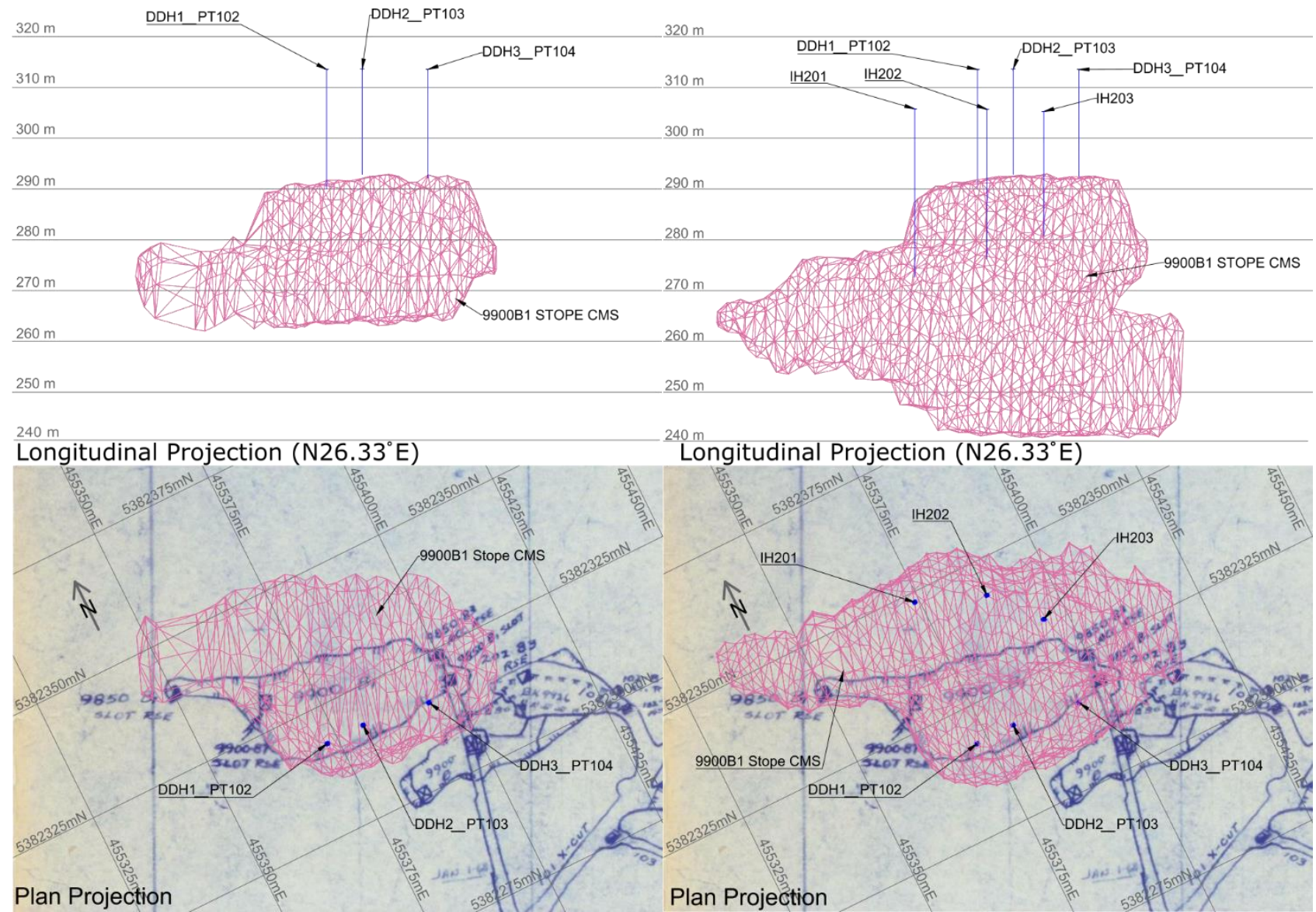

(a)

(b)

Figure 7 Long section and plan view projections of the sonar scan wireframe of 9900B1 Stope; (a) Phase 1 sonar survey; and, (b) Phase 2 sonar survey

The full height of the stope could not be captured during the first phase due to the location of the boreholes in the crown and the geometry of the stope. The proximity of the scans to the back of the stope is estimated to be close, as the three Phase 1 boreholes along strike intersect the stope at approximately the same depth through the crown pillar. Borehole camera surveys were completed through each borehole to the depths shown in Figure 7. 
The MNDM drilled three additional boreholes to permit a deeper sonar survey. This second survey captured blind spots in the first survey along the north-western section where the stope narrows, and captured nearly all of the stope void.

The volume of the 9900B1 Stope from the Phase 1 sonar scan wireframe is $28,700 \mathrm{~m}^{3}$, an approximate $79 \%$ increase from the 2009 estimated volume. The Phase 2 sonar scan wireframe volume is $63,000 \mathrm{~m}^{3}$, an increase of approximately $294 \%$ from the 2009 estimated volume and a 120\% increase from the Phase 12017 survey.

\section{Conclusion}

Remote inspection and surveying of underground voids is a critical part of assessing the stability of underground voids, planning the reclamation of these voids and confirming fill volumes required and placement of the fill. Borehole-deployed cameras, CMS surveys, and sonar scanners all serve this purpose; their application depends on the circumstances. Borehole cameras can provide quick visual surveys that, when combined with custom secondary lighting, can provide detailed qualitative data on void geometry and stability. CMS surveys provide high-resolution scaled and georeferenced 3D surveys of voids that allow accurate volume estimates and input into numerical models. Borehole sonar represents a relatively new tool with the ability to generate results similar to a CMS survey in flooded excavations. In addition to providing 3D geometry, due to increased light attenuation, sonar may often be the only way to inspect flooded workings. Surveying of underground voids provides the information required to make the best possible decisions when planning reclamation work, which can significantly reduce the final cost and schedule uncertainty.

\section{Acknowledgement}

The authors acknowledge the contribution of Chris MacInnis, Indigenous and Northern Affairs Canada, and Stan Kaczmarek, Ontario Ministry of Northern Development and Mines, to this paper.

\section{References}

Allegheny Instruments, Inc. 2016, GeoVISION Borehole Video System, Allegheny Instruments, Inc., Monterey, viewed 13 July 2017 , http://www.alleghenyinstruments.com/

Imagenex Technology Corp. 2016, Imagenex 881A, Imagenex Technology Corp., Port Coquitlam, viewed 24 July 2017, http://imagenex.com/products/881a-imaging

Renishaw plc 2017, Cavity Auto-scanning Laser System, Renishaw plc, Gloucestershire, viewed 13 July 2017, http://www.renishaw.com/en/c-als 
